\title{
A Parametric Study of the Impact of the Cooling Water Site Specific Conditions on the Efficiency of a Pressurized Water Reactor Nuclear Power Plant
}

\author{
Mohamed M. A. Ibrahim and Mohamed R. Badawy \\ Nuclear Power Plants Authority, 4 El-Nasr Avenue, Nasr City, P.O. Box 8191, Nasr City 11371, Cairo, Egypt \\ Correspondence should be addressed to Mohamed M. A. Ibrahim; mraoufsalah@yahoo.com
}

Received 6 April 2014; Revised 24 July 2014; Accepted 11 August 2014; Published 28 August 2014

Academic Editor: Adem Acir

Copyright (C) 2014 M. M. A. Ibrahim and M. R. Badawy. This is an open access article distributed under the Creative Commons Attribution License, which permits unrestricted use, distribution, and reproduction in any medium, provided the original work is properly cited.

\begin{abstract}
In this study, the thermal analysis for the impact of the cooling seawater site specific conditions on the thermal efficiency of a conceptual pressurized water reactor nuclear power plant (PWR NPP) is presented. The PWR NPP thermal performance depends upon the heat transfer analysis of steam surface condenser accounting for the key parameters such as the cooling seawater salinity and temperature that affect the condenser overall heat transfer coefficient and fouling factor. The study has two aspects: the first one is the impact of the temperature and salinity within a range of $(290 \mathrm{~K}-310 \mathrm{~K}$ and $0.00-60000 \mathrm{ppm})$ on the seawater thermophysical properties such as density, specific heat, viscosity, and thermal conductivity that reflect a reduction in the condenser overall heat transfer coefficient from $2.25 \mathrm{~kW} / \mathrm{m}^{2} \mathrm{~K}$ to $1.265 \mathrm{~kW} / \mathrm{m}^{2} \mathrm{~K}$ at temperature and salinity of $290 \mathrm{~K}$ and $0.00 \mathrm{ppm}$ and also from $2.35 \mathrm{~kW} / \mathrm{m}^{2} \mathrm{~K}$ to $1.365 \mathrm{~kW} / \mathrm{m}^{2} \mathrm{~K}$ at temperature and salinity of $310 \mathrm{~K}$ and $60000 \mathrm{ppm}$, whereas the second aspect is the fouling factor variations due to the seawater salinity. The analysis showed that the two aspects have a significant impact on the computation of the condenser overall heat transfer coefficient, whereas the increase of seawater salinity leads to a reduction in the condenser overall heat transfer coefficient.
\end{abstract}

\section{Introduction}

Thermal power plants are built for prescribed specific design conditions based on the targeted power demand, metallurgical limits of structural elements, statistical values of environmental conditions, and so forth. At design stage, a cooling medium temperature is chosen for each site considering long term average climate conditions. However, the working conditions deviate from the nominal operating conditions in practice. For this reason, efficiency in electricity production is affected by the deviation of the instantaneous operating temperature and salinity of seawater cooling water of nuclear power plant from the design temperature of the cooling medium extracted from environmental to transfer waste heat to the atmosphere via condenser.

In the literature, there are few works published such as that of Kokaji [1] which indicated that all the nuclear power plants in Japan are located on the seaside and use a great amount of seawater for cooling condenser like fossil power generation plants. The resultant thermal discharge which may have an impact on the environmental of the surrounding areas is one of the most important issues to be given a serious consideration, next to prevention from affecting the local residents by released radioactive material. The author pointed out that there are three themes which are related to our commitments to the effective management of thermal discharge from our nuclear power plants which will be introduced by taking an example of Takahoma power plant (which generates $3392 \mathrm{MW}$ in total by four $800 \mathrm{MW}$ class units):

(i) specifications of the intake and discharge systems and major items to be examined for the protection of the natural environment;

(ii) evaluation and restriction related to the impact of thermal discharge on the natural environment;

(iii) outline of our laboratory to utilize thermal discharge. 
Durmayaz and Sogut [2] performed an iterative condenser heat balance model to determine the functional relationship between the cooling water temperature and condenser pressure. The authors consider a cycle analysis for the PWR NPP considered in their study that is carried out to determine the off-design heat balance conditions originating from temperature change of cooling medium. Also, the authors concluded that the power output and the thermal efficiency decrease by approximately 0.42 and $0.12 \%$, respectively, for $1^{\circ} \mathrm{C}$ increase in the temperature of the coolant extracted from environment. Nebot et al. [3] performed a kinetic model for fouling evolution prediction. The authors account for the effects of water velocity and tube material on fouling deposition and obtained the maximum asymptotic limit of the thermal resistance decrease as velocity increases. After the application of the model it can also be concluded that in all seasons of the year, titanium tubes are more prone to be fouled, although the process is slower than with brass tubes. Kapooria et al. [4] performed an analytical investigation concerning the thermal analysis and design considerations of a steam condenser. The authors showed that the use of a hybrid steam condenser enables higher efficiency of the steam power plant by lowering condenser steam pressure and increasing the vacuum inside the condenser. The parametric study accounts for an energy balance and heat transfer analysis. Therefore, the parametric study is performed to assess the impact of the change in cooling medium temperature and salinity on the thermal efficiency of the conceptual PWR NPP. The objective of this parametric study is to establish a theoretical methodology to evaluate the impact of thermophysical properties of cooling water on the PWR NPP steam surface condenser overall heat transfer coefficient and fouling factor within specific designed range of cooling water temperature and salinity point of view. A model for condenser heat balance is developed to determine the functional relationship between the cooling water temperature and salinity and the condenser pressure considering the fact that saturation conditions exists in condenser and there is a finite amount of temperature difference between this saturation temperature and the cooling water exit temperature. Employing this condenser heat balance, the analysis is carried out to determine the off-design heat balance conditions and thermal efficiency for prescribed range of cooling water temperatures and salinity.

\section{Model Description}

A nuclear power plant of PWR type has two main parts, namely, primary and secondary loops. The primary loop includes the recirculation pump that pumps the coolant through the nuclear reactor and steam generators in closed loops while the secondary loop of the PWR NPP includes high and low pressure turbines, a moisture separator, reheater, a feedwater heater, a main condensate pump, and a condenser. The model considering all thermophysical properties of seawater such as density, specific heat, viscosity, and thermal conductivity is indicated as function of both temperature and salinity. It is important to be able to recognize these seawater thermophysical properties in order to work with good knowledge of its characteristics and behavior. The source of the thermophysical properties mentioned in this model is taken from $[5,6]$ as a function of both cooling water temperature and salinity.

The developed mathematical model is based on the heat transfer analysis of the power plant condenser through the use of salt water in cooling instead of fresh water. This model enables verifying the impact of cooling water sitespecific conditions variables such as cooling water salinity and temperature on the thermal performance and efficiency of the PWR NPP through the variation in thermodynamic properties and parameters that govern the rate of heat transfer and the increase of fouling factor during the plant operation.

The developed mathematical model undergoes the following assumptions:

(i) the variation of the brine physical and thermodynamic properties such as density, thermal conductivity, viscosity, and specific heat at constant pressure with change in both the brine temperature and salinity;

(ii) no heat losses to the surroundings because all parts of the condenser are well insulated and operate at relatively low temperature;

(iii) the effect of the presence of noncondensable gases on the heat transfer coefficients in the condenser being neglected;

(iv) constant condenser heat transfer area and heat load.

For the reference case (use of fresh water) salt-free cooling water and zero fouling are assumed. According to Rajput [7], the overall heat transfer coefficient is determined as

$$
U_{o, r}=\frac{1}{\left(1 / h_{i}\right)+\left(1 / h_{o}\right)+F},
$$

where $h_{o}$ is outer heat transfer coefficient of convection, $\mathrm{kW} / \mathrm{m}^{2} \mathrm{~K}, h_{i}$ is internal heat transfer coefficient of convection, and $\mathrm{kW} / \mathrm{m}^{2} \mathrm{~K}, F$ is fouling factor, $\mathrm{m}^{2} \mathrm{~K} / \mathrm{kW}$.

The average convective heat transfer coefficient for film condensation on the outer surfaces of a vertical tier of $N_{h}$ horizontal tubes may be expressed as

$$
\begin{aligned}
h_{o}= & 0.725 \\
& \times\left(\frac{g \times \rho_{L} \times\left(\rho_{L}-\rho_{V}\right) \times h_{\mathrm{fg}} \times(k / 1000)^{3}}{\mu_{L} \times\left(T_{\mathrm{st}}-T_{w}\right) \times N_{h} \times d_{o}}\right)^{0.25} .
\end{aligned}
$$

For $\operatorname{Re} \geq 10,000$ and $0.6 \leq \operatorname{Pr} \leq 160$, the Dittus-Boelter correlation is applied to estimate the average heat transfer coefficient for forced flow inside circular tubes as follows:

$$
h_{i}=\left(0.023 \operatorname{Re}^{0.8} \operatorname{Pr}^{0.4}\right) \times \frac{k_{b}}{d_{i}} .
$$

Both Reynolds number and Prandtl number are calculated as a function of the thermophysical properties as follows:

$$
\operatorname{Re}=\frac{\rho_{b} * V * d_{i}}{\mu_{b}}, \quad \operatorname{Pr}=\frac{\mu_{b} * c_{p b}}{k_{b}} .
$$


The internal heat transfer coefficient is calculated in the two cases: first, for the relevance case in which fresh water of almost zero salinity is used for cooling and second, for using saline water including changing the physical properties with the cooling water salinity. Assuming constant condenser heat load and heat transfer area, the following relationship can be deduced:

$$
\frac{\theta_{r}}{\theta_{\text {new }}}=\frac{U_{\text {new }}}{U_{r}},
$$

where $\theta_{r}=$ logarithmic mean temperature difference for the reference case, $\theta_{\text {new }}=$ logarithmic mean temperature difference for the case of using saline water, and $U_{\text {new }}=$ overall heat transfer coefficient in case of using saline water.

The logarithmic mean temperature difference for the reference case is

$$
\theta_{r}=\frac{T_{\mathrm{co}}-T_{\mathrm{ci}}}{\ln \left(\left(T_{\mathrm{st}}-T_{\mathrm{ci}}\right) /\left(T_{\mathrm{st}}-T_{\mathrm{co}}\right)\right)},
$$

where $T_{\mathrm{ci}}=$ cooling water inlet temperature, ${ }^{\circ} \mathrm{C}, T_{\text {co }}=$ cooling water outlet temperature, ${ }^{\circ} \mathrm{C}$, and $T_{\text {st }}=$ exhausted steam temperature, ${ }^{\circ} \mathrm{C}$.

From (6) the logarithmic mean temperature difference for the case of using saline water $\left(\theta_{\text {new }}\right)$ is calculated as

$$
\theta_{\text {new }}=\frac{\theta_{r} \times U_{r}}{U_{\text {new }}} .
$$

Also, $\left(\theta_{\text {new }}\right)$ can be expressed as

$$
\theta_{\text {new }}=\frac{T_{\text {co }}-T_{\mathrm{ci}}}{\ln \left(\left(T_{s, \text { new }}-T_{\mathrm{ci}}\right) /\left(T_{s, \text { new }}-T_{\mathrm{co}}\right)\right)} .
$$

The previous equation can be expressed also in the following form:

$$
T_{s, \text { new }}=\frac{T_{\mathrm{ci}}-\alpha T_{\mathrm{co}}}{1-\alpha}
$$

where $T_{s, \text { new }}=$ the new turbine exhausted temperature, ${ }^{\circ} \mathrm{C}$. Consider

$$
\alpha=e^{\left(\left(T_{\mathrm{co}}-T_{\mathrm{ci}}\right) / \theta_{\text {new }}\right)} .
$$

By estimating the new value of exhausted steam temperature, the new thermal efficiency is calculated from the following approach:

$$
\eta_{\text {new }}=\eta_{r}-\left[\left(\frac{\eta_{t} \times \eta_{\mathrm{cr}}}{1-\eta_{t} \times \eta_{\mathrm{cr}}}\right) \times\left(1-\eta_{r}\right)\right],
$$

where $\eta_{t}$ is turbine isentropic efficiency $\approx 80.0 \%$ and $\eta_{\mathrm{cr}}$ is Carnot efficiency and is calculated as

$$
\eta_{\mathrm{cr}}=\frac{T_{s, \text { new }}-T_{\mathrm{st}}}{T_{s, \text { new }}+273}
$$

The previous approach is acceptable specially when considering small temperature variation ranges.

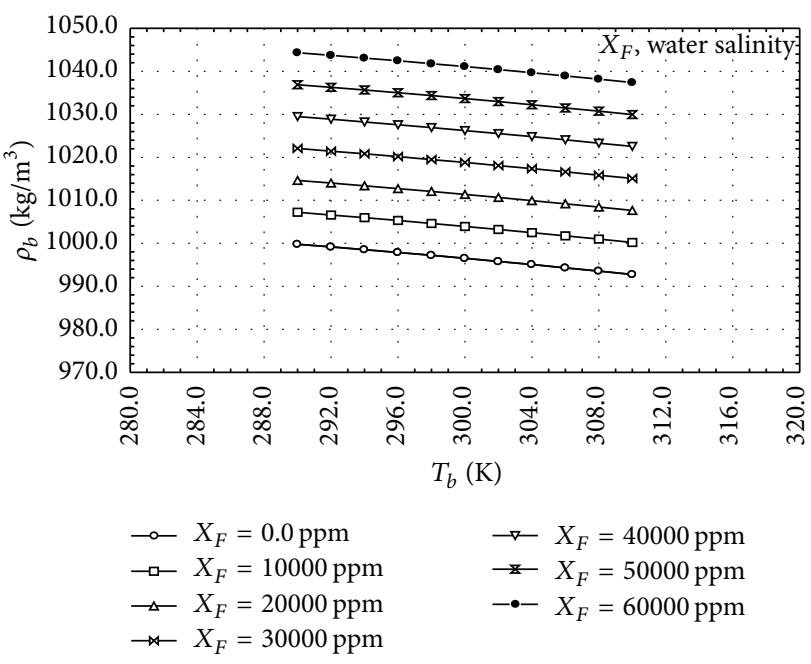

FIGURE 1: Effect of seawater salinity and temperature on the density.

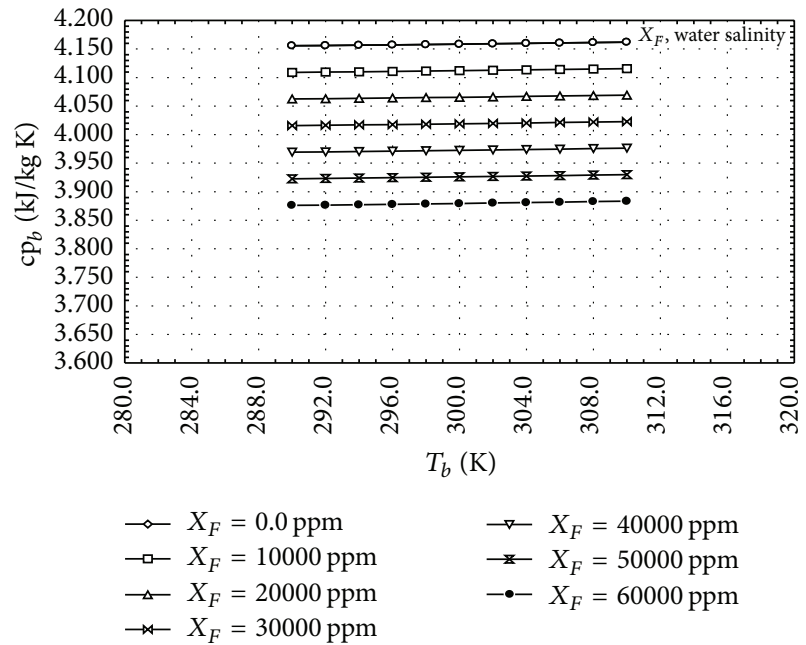

FIGURE 2: Effect of seawater salinity and temperature on the specific heat.

\section{Results and Discussion}

The condenser key parameters that affect the thermal performance are studied and analyzed for the PWR NPP with the site specific conditions. These parameters are condenser overall heat transfer coefficient, condensing steam temperature, pressure, and overall thermal efficiency, which are affected by the fouling factor and salinity of seawater. The thermophysical properties of condenser cooling water seawater density, specific heat at constant pressure, thermal conductivity, and dynamic viscosity have a significant effect on seawater salinity from 0.0 to $60000 \mathrm{ppm}$ and temperature from 290 to $310 \mathrm{~K}$ which lead to reduction in the condenser overall heat transfer coefficient, respectively. Figure 1 shows the effect of condensing water density on both temperature and salinity. The seawater density increases as temperature increases, but for the constant seawater salinity, the density decreases as temperature increases due to the increase in 


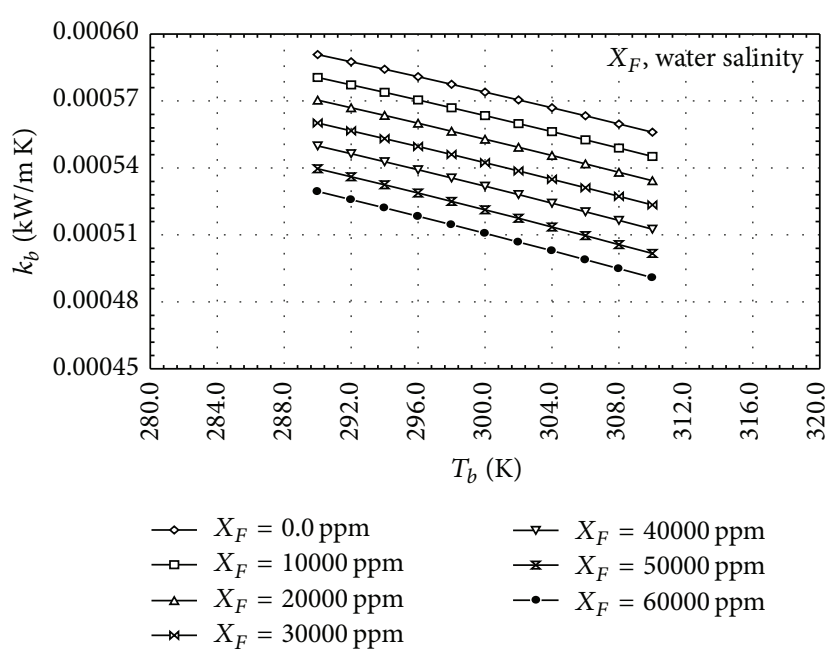

FIGURE 3: Effect of seawater salinity and temperature on the thermal conductivity.

the seawater volume. Figure 2 shows the effect of both cooling water temperature and salinity on the specific heat at constant pressure. The cooling water specific heat at constant pressure decreases as salinity increases, but for the constant seawater salinity, the specific heat at constant pressure increases as temperature increases. Figure 3 shows the effect of both cooling water temperature and salinity on the thermal conductivity. The cooling water conductivity decreases as salinity increases, but for the constant seawater salinity, the conductivity decreases as temperature increases. Figure 4 shows the effect of seawater dynamic viscosity on both temperature and salinity. The cooling water dynamic viscosity decreases as temperature increases, but for the constant seawater temperature, the dynamic viscosity increases as salinity increases due to the increase of the flow resistance.

The overall thermal efficiency of PWR NPP depends on the thermal performance of the steam surface condenser. One of the main key parameters that affect the condenser thermal performance is the overall heat transfer coefficient. Any variations of the overall heat transfer coefficient appear on the condenser performance and reflect on the overall thermal efficiency of PWR NPP. The overall heat transfer coefficient is mainly a function of the internal heat transfer coefficient, external heat transfer coefficient, and fouling factor, respectively. Figure 5 shows the change in the overall heat transfer coefficient with temperature and salinity of cooling seawater inlet. The overall heat transfer coefficient decreases as seawater salinity increases and seawater temperature decreases due to changes in thermophysical properties that decrease the internal heat transfer coefficient. In addition, the decrease in internal heat transfer coefficient due to reduction in the condenser wall temperature causes a decrease in the condenser external heat transfer coefficient.

The operating experience for the steam surface condenser indicated that the fouling factor is formed due to the accumulation of salts gradually through the operating duration which forms a scale on the internal tube side. These scales increase

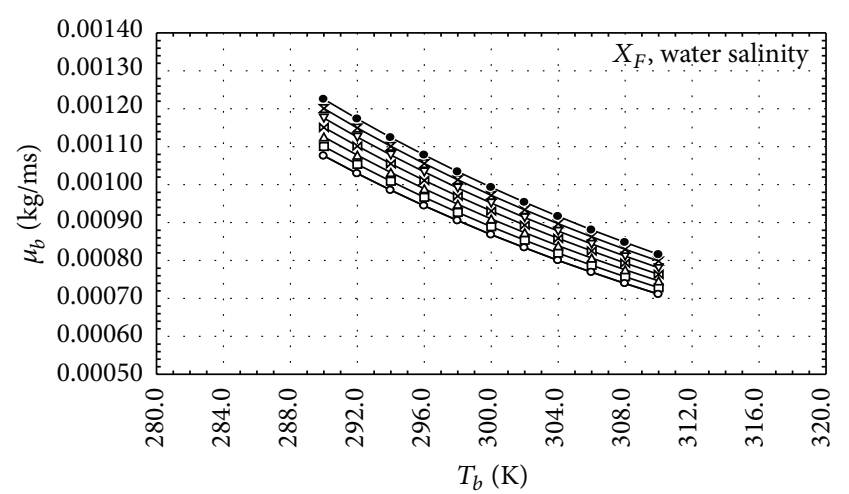

$$
\begin{array}{llrl}
\multimap X_{F} & =0.0 \mathrm{ppm} & & \rightarrow X_{F}=40000 \mathrm{ppm} \\
\multimap-X_{F}=10000 \mathrm{ppm} & & \rightarrow X_{F}=50000 \mathrm{ppm} \\
\multimap-X_{F}=20000 \mathrm{ppm} & & \rightarrow-X_{F}=60000 \mathrm{ppm} \\
\rightarrow \bowtie X_{F}=30000 \mathrm{ppm} & &
\end{array}
$$

FIGURE 4: Effect of seawater salinity and temperature on the viscosity.

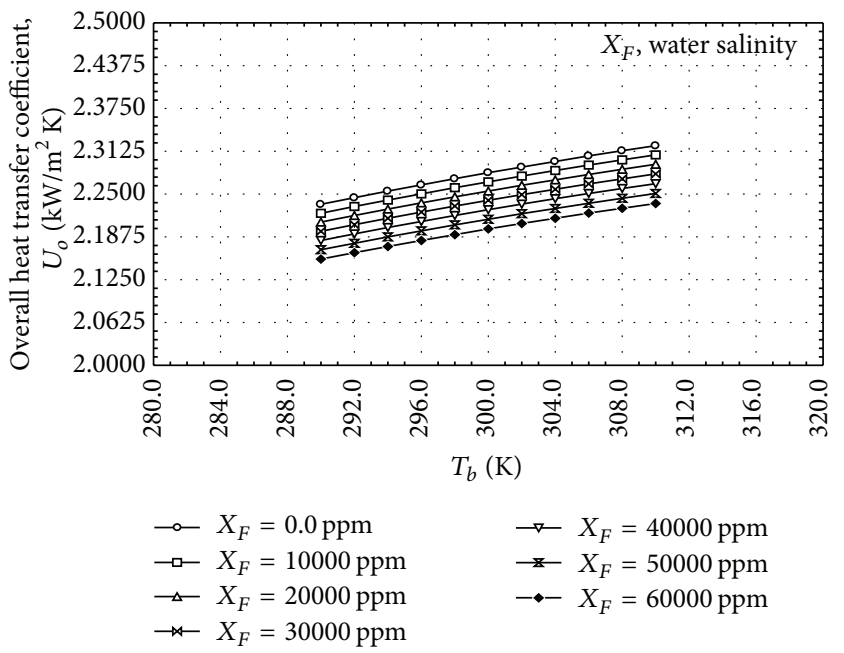

FIGURE 5: Effect of cooling water salinity and temperature on the condenser overall heat transfer coefficient.

the thermal resistance in terms of fouling factor in range of 0.1 to $0.35 \mathrm{~kW} / \mathrm{m}^{2} \mathrm{~K}$ according to experience. Figure 6 shows the change in the overall heat transfer coefficient with salinity and temperature of cooling seawater inlet whereas the overall heat transfer coefficient decreases as seawater salinity and fouling factor increase and seawater temperature decreases due to thermophysical properties changes.

Figure 7 shows the change in cooling water salinity and temperature inlet in terms of $290 \mathrm{~K}$ to $310 \mathrm{~K}$ whereas the 5 degrees Kelvin takes place in condensate temperature from $306.5 \mathrm{~K}$ to $308 \mathrm{~K}$ (1.5 degrees Kelvin). Therefore, with constant seawater temperature, fouling factor, and salinity varies from 0.0 to $60000 \mathrm{ppm}$ will rise the condenser temperature by $15 \mathrm{~K}$ and also, increasing in condenser pressure to 0.04 bar respectively, as shown in Figure 8.

The increasing in the condenser pressure and temperature causes a reduction in the amount of useful work produced 


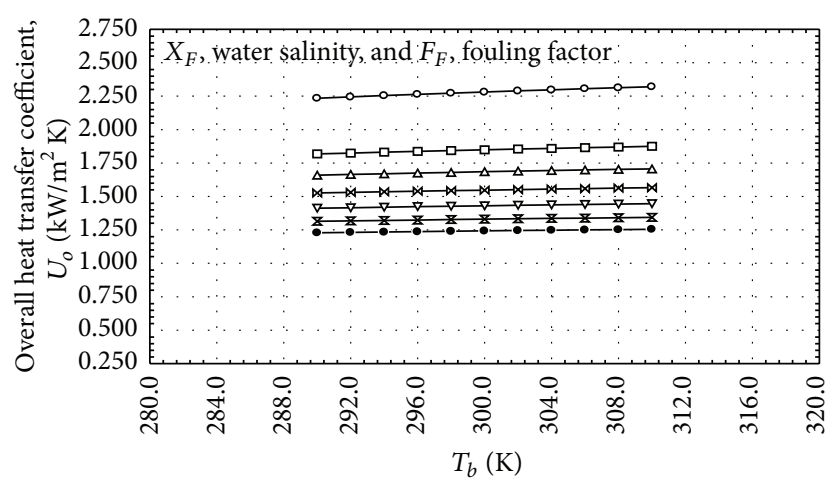

$$
\begin{aligned}
& \multimap X_{F}=0.0 \mathrm{ppm} \text { and } F_{F}=0.0 \mathrm{~m}^{2} \mathrm{~K} / \mathrm{kW} \\
& \rightarrow-X_{F}=10000 \mathrm{ppm} \text { and } F_{F}=0.10 \mathrm{~m}^{2} \mathrm{~K} / \mathrm{kW} \\
& \triangle-X_{F}=20000 \mathrm{ppm} \text { and } F_{F}=0.15 \mathrm{~m}^{2} \mathrm{~K} / \mathrm{kW} \\
& \rightarrow \bowtie X_{F}=30000 \mathrm{ppm} \text { and } F_{F}=0.20 \mathrm{~m}^{2} \mathrm{~K} / \mathrm{kW} \\
& \rightarrow-X_{F}=40000 \mathrm{ppm} \text { and } F_{F}=0.25 \mathrm{~m}^{2} \mathrm{~K} / \mathrm{kW} \\
& \rightarrow-X_{F}=50000 \mathrm{ppm} \text { and } F_{F}=0.30 \mathrm{~m}^{2} \mathrm{n} \mathrm{K} / \mathrm{kW} \\
& -\bullet X_{F}=60000 \mathrm{ppm} \text { and } F_{F}=0.35 \mathrm{~m}^{2} \mathrm{~K} / \mathrm{kW}
\end{aligned}
$$

FIGURE 6: Effect of seawater salinity, temperature, and fouling factor on the condenser overall heat transfer coefficient.

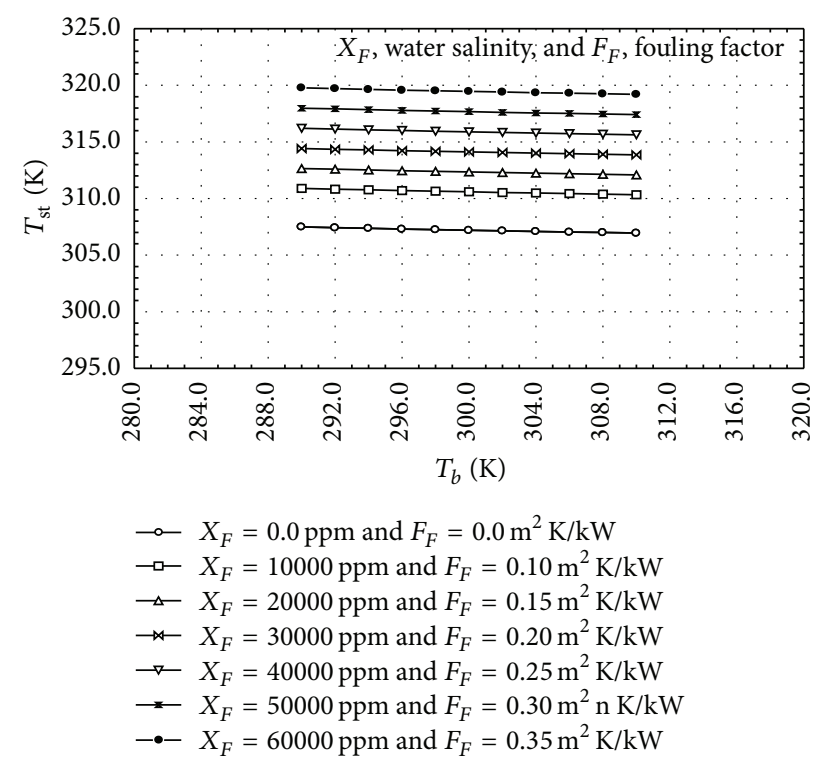

FIGURE 7: Effect of seawater salinity, temperature, and fouling factor on the condensate temperature.

from the steam turbine and, respectively, the overall thermal efficiency of PWR NPPas referred to in Figure 9. This figure indicated that two percentage reduction in the overall efficiency that means a ratio of $6 \%$ changes approximately compared to the relevance of plant efficiency.

\section{Conclusions}

The steam surface condenser remains among one of the key components of PWR NPP because the overall thermal efficiency of PWR NPP depends upon the thermal performance

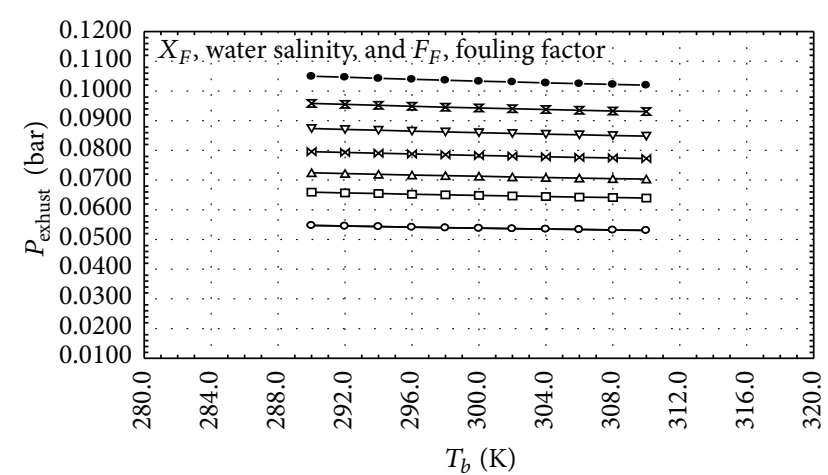

$$
\begin{aligned}
& \multimap X_{F}=0.0 \mathrm{ppm} \text { and } F_{F}=0.0 \mathrm{~m}^{2} \mathrm{~K} / \mathrm{kW} \\
& \rightarrow-X_{F}=10000 \mathrm{ppm} \text { and } F_{F}=0.10 \mathrm{~m}^{2} \mathrm{~K} / \mathrm{kW} \\
& \square-X_{F}=20000 \mathrm{ppm} \text { and } F_{F}=0.15 \mathrm{~m}^{2} \mathrm{~K} / \mathrm{kW} \\
& \rightarrow-X_{F}=40000 \mathrm{ppm} \text { and } F_{F}=0.25 \mathrm{~m}^{2} \mathrm{~K} / \mathrm{kW} \\
& \rightarrow-X_{F}=50000 \mathrm{ppm} \text { and } F_{F}=0.30 \mathrm{~m}^{2} \mathrm{n} \mathrm{K} / \mathrm{kW} \\
& \rightarrow-X_{F}=60000 \mathrm{ppm} \text { and } F_{F}=0.35 \mathrm{~m}^{2} \mathrm{~K} / \mathrm{kW}
\end{aligned}
$$

FIGURE 8: Effect of seawater salinity, temperature, and fouling factor on the condensate pressure.

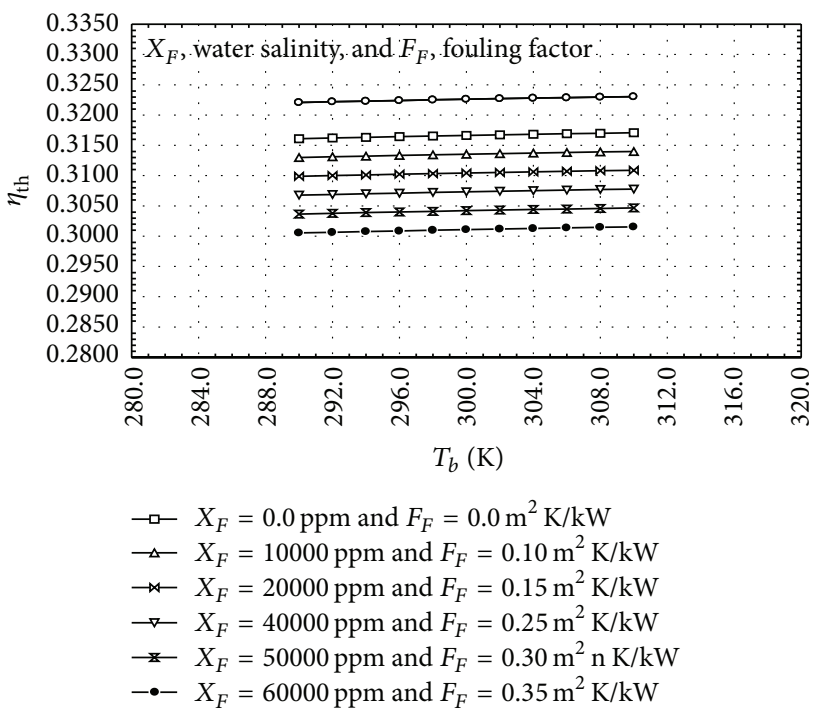

FIGURE 9: Effect of seawater salinity, temperature, and fouling factor on the thermal efficiency.

analysis of condenser. The present model considering the condenser heat transfer analysis is developed to determine the functional relationship between the cooling water temperature and PWR NPP thermal efficiency accounting for the salinity and temperature of condenser cooling water. The study is carried out to determine the off-design heat balance conditions originating from salinity and temperature change of cooling medium. It can be concluded that the thermal efficiency decreases by approximately 0.2 , respectively, for $5 \mathrm{~K}$ and $10000 \mathrm{ppm}$ increase in temperature and salinity of inlet seawater cooling inlet to the steam surface condenser. From the point of view of constructing a PWR NPP in Egypt, 
this study consequently proves that if seawater is used as cooling medium in condenser, then the thermal efficiency of PWR NPP will be reduced due to an increase in the condenser pressure. The increase in the condenser pressure and temperature causes a reduction in the amount of useful work produced from the steam turbine and, respectively, the overall thermal efficiency of PWR NPP as it was indicated that two percentage reduction in the overall efficiency that means a ratio of $6 \%$ changes approximately compared to the relevance of plant efficiency.

\section{Nomenclature}

\author{
a: Constant \\ c: Specific heat $[\mathrm{kJ} / \mathrm{kg} \mathrm{K}]$ \\ $d$ : Pipe diameter $[\mathrm{m}]$ \\ $F$ : Fouling factor $\left[\mathrm{m}^{2} \mathrm{~K} / \mathrm{kW}\right]$ \\ $g$ : Acceleration due to gravity $\left[\mathrm{m} / \mathrm{s}^{2}\right]$ \\ $h$ : Heat transfer coefficient $\left[\mathrm{kW} / \mathrm{m}^{2} \mathrm{~K}\right]$ \\ $h$ : Latent heat $[\mathrm{kJ} / \mathrm{kg}]$ \\ $k$ : Thermal conductivity $[\mathrm{kW} / \mathrm{m} \mathrm{K}]$ \\ $L$ : Tube length $[\mathrm{m}]$ \\ $N$ : Number of tubes \\ $P$ : Pressure [bar] \\ $T$ : Temperature $[\mathrm{K}]$ \\ $U$ : Heat transfer coefficient $\left[\mathrm{kW} / \mathrm{m}^{2} \mathrm{~K}\right]$ \\ $V$ : Cooling water velocity $[\mathrm{m} / \mathrm{s}]$ \\ $X$ : Salinity [ppm].
}

\section{Greek Symbols}

$\eta$ : Efficiency

$\rho$ : Density $\left[\mathrm{kg} / \mathrm{m}^{3}\right]$

$\mu$ : Dynamic viscosity $[\mathrm{kg} / \mathrm{ms}]$

$\theta$ : Logarithmic mean temperature $[\mathrm{K}]$.

\section{Conflict of Interests}

The authors declare that there is no conflict of interests regarding the publication of this paper.

\section{References}

[1] I. Kokaji, "The present status for thermal discharge of nuclear power plant," Progress in Nuclear Energy, vol. 29, pp. 413-420, 1995.

[2] A. Durmayaz and O. S. Sogut, "Influence of cooling water temperature on the efficiency of a pressurized-water reactor nuclear-power plant," International Journal of Energy Research, vol. 30, no. 10, pp. 799-810, 2006.

[3] E. Nebot, J. F. Casanueva, T. Casanueva, and D. Sales, "Model for fouling deposition on power plant steam condensers cooled with seawater: effect of water velocity and tube material," International Journal of Heat and Mass Transfer, vol. 50, no. 1718, pp. 3351-3358, 2007.

[4] R. k. Kapooria, S. Kumar, and K. S. Kasana, "Technological investigations and efficiency analysis of steam heat exchange condenser: conceptual design of hybrid steam condenser," The Journal of Energy in Southern Africa, vol. 19, pp. 35-45, 2009.

[5] G. Sieder and H. Peter, "Physical properties (general) of seawater," in LANDOLT-BORS TEIN: Numerical Data Functional Relationship in Science and Technology, vol. V13a, pp. 233-264, Springer, Berlin, Germany, 1986.

[6] E. E. Tarifa and N. J. Seenna, “Desalination,” Desalination, vol. 138, p. 349, 2001.

[7] R. K. Rajput, "Power Plant Engineering," LAXMI Publication (P) LTD, 1995.

\author{
Subscripts \\ $b$ : Brine \\ cw: Cooling water \\ $i$ : Inlet \\ $l$ : Liquid \\ $o, r$ : Outlet or overall \\ $w$ : Wall \\ fg: Heat of vaporization \\ st: Steam or vapor saturation.
}

\section{Dimensionless Parameters}

Pr: Prandtl number

Re: Reynolds number.

\section{Abbreviations}

PWR: Pressurized water reactor

NPP: Nuclear power plant. 


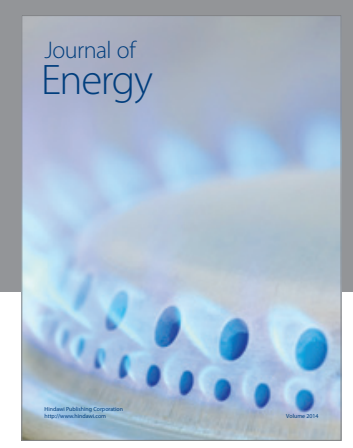

Journal of

Industrial Engineering
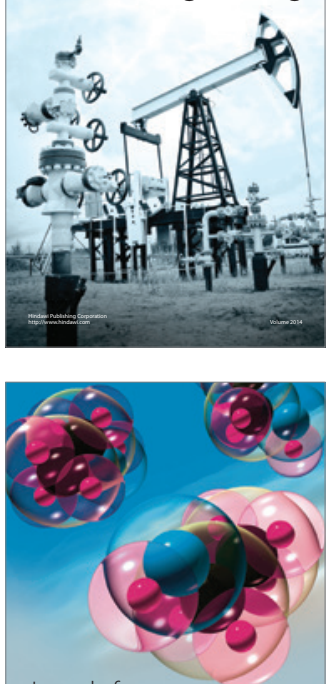

Fuels
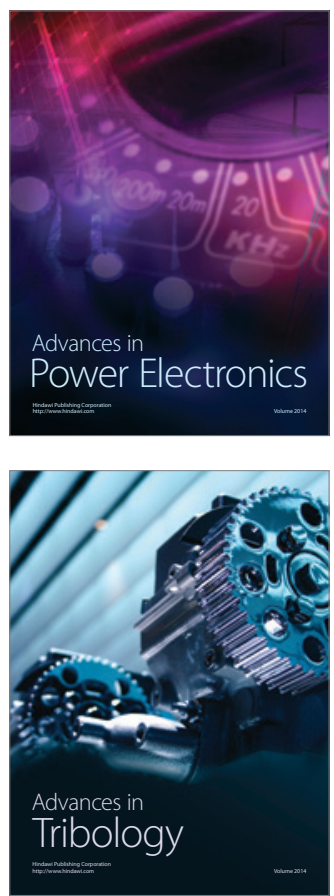

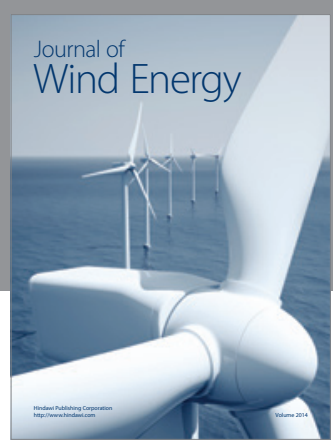

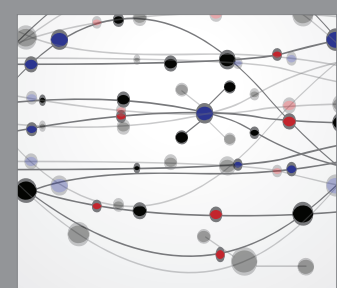

The Scientific World Journal

Submit your manuscripts at http://www.hindawi.com

Journal of

Structures
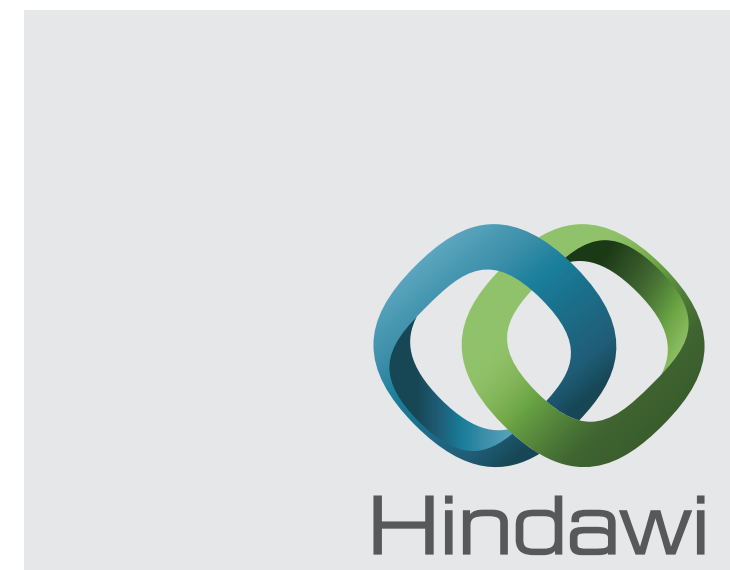

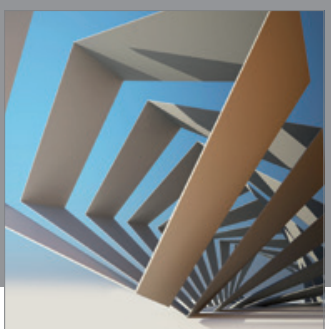

Rotating

Machinery
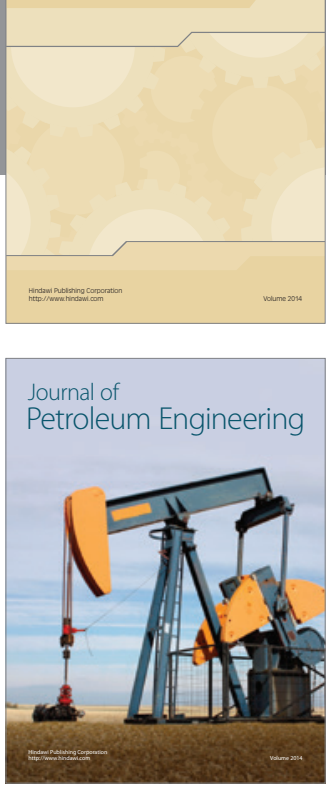

Journal of

Solar Energy
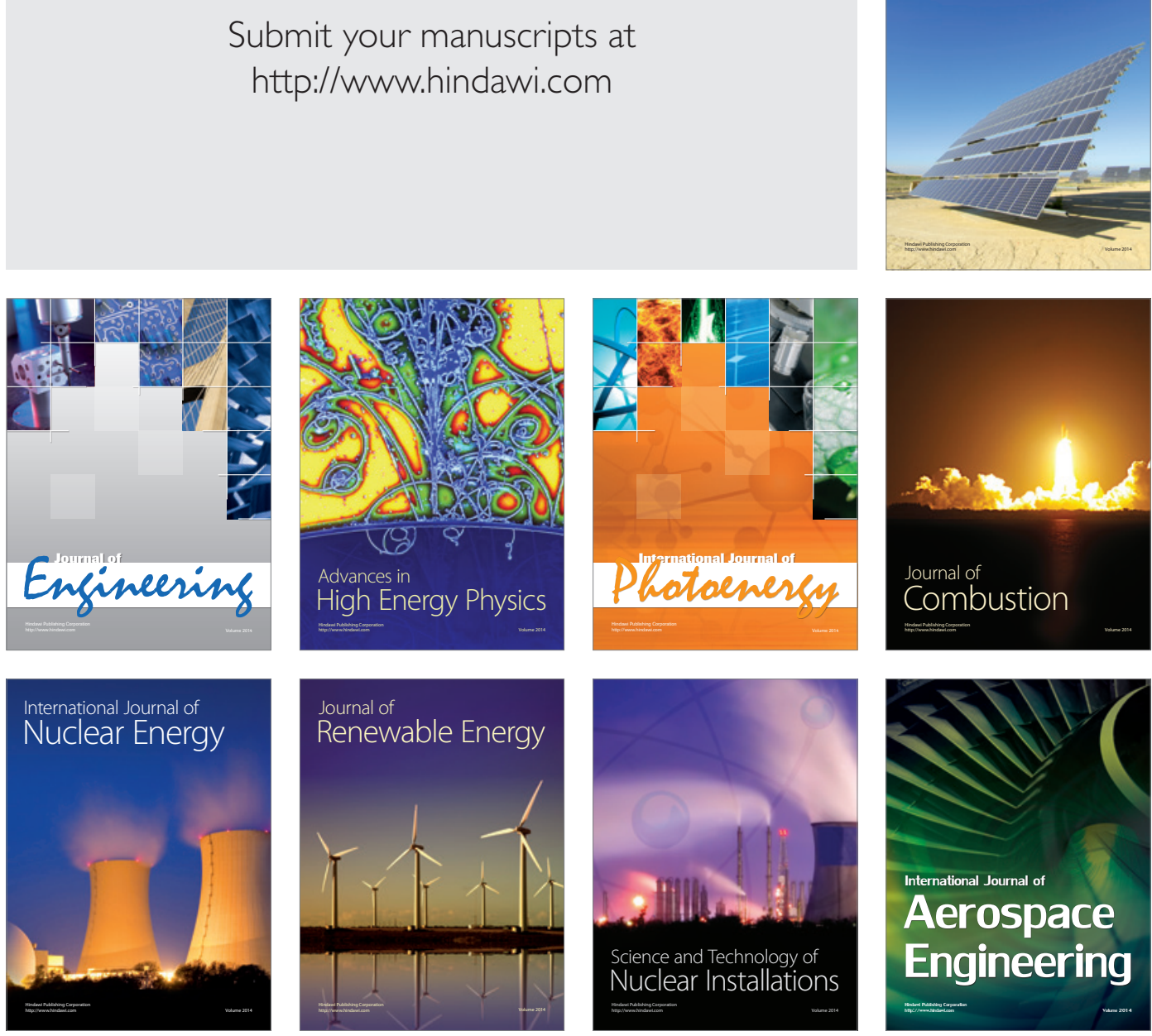